\title{
Cross-habitat interactions among bivalve species control community structure on intertidal flats
}

\author{
Serena Donadi, ${ }^{1,8}$ Tuisse van der Heide, ${ }^{2}$ Els M. van der Zee, ${ }^{3,4}$ Johan S. Eklöf, ${ }^{1,5,6}$ Johan van de Koppel,,${ }^{2,7}$ \\ Ellen J. Weerman, ${ }^{2}$ Theunis Piersma, ${ }^{3,4}$ Han OlfF, ${ }^{2}$ and Britas Klemens Eriksson ${ }^{1}$ \\ ${ }^{1}$ Department of Marine Benthic Ecology and Evolution, Centre for Ecological and Evolutionary Studies (CEES), \\ University of Groningen, P.O. Box 11103, 9700 CC Groningen, The Netherlands \\ ${ }^{2}$ Community and Conservation Ecology Group. Centre for Ecological and Evolutionary Studies (CEES). University of Groningen, \\ P.O. Box 11103, $9700 \mathrm{CC}$ Groningen, The Netherlands \\ ${ }^{3}$ Animal Ecology Group, Centre for Ecological and Evolutionary Studies (CEES), University of Groningen, P.O. Box 11103, \\ 9700 CC Groningen, The Netherlands \\ ${ }^{4}$ Department of Marine Ecology, Royal Netherlands Institute for Sea Research (NIOZ), P.O. Box 59, 1790 AB Den Burg, Texel, \\ The Netherlands \\ ${ }^{5}$ Department of Biology and Environmental Science. University of Gothenburg, Box 461, SE-405 30 Gothenburg, Sweden \\ ${ }^{6}$ Department of Systems Ecology, Stockholm University, SE-10691 Stockholm, Sweden \\ ${ }^{7}$ Spatial Ecology Department, Royal Netherlands Institute for Sea Research (NIOZ), P.O. Box 140, 4400 AC, Yerseke, \\ The Netherlands
}

\begin{abstract}
Increasing evidence shows that spatial interactions between sedentary organisms can structure communities and promote landscape complexity in many ecosystems. Here we tested the hypothesis that reef-forming mussels (Mytilus edulis L.), a dominant intertidal ecosystem engineer in the Wadden Sea, promote abundances of the burrowing bivalve Cerastoderma edule L. (cockle) in neighboring habitats at relatively long distances coastward from mussel beds. Field surveys within and around three mussel beds showed a peak in cockle densities at 50-100 m toward the coast from the mussel bed, while cockle abundances elsewhere in the study area were very low. Field transplantation of cockles showed higher survival of young cockles (2-3 years old) and increased spat fall coastward of the mussel bed compared to within the bed and to areas without mussels, whereas growth decreased within and coastward of the mussel bed. Our measurements suggest that the observed spatial patterns in cockle numbers resulted from (1) inhibition effects by the mussels close to the beds due to preemptive algal depletion and deteriorated sediment conditions and (2) facilitation effects by the mussels farther away from the beds due to reduction of wave energy. Our results imply that these spatial, scale-dependent interactions between reef-forming ecosystem engineers and surrounding communities of sedentary benthic organisms can be an important determinant of the large-scale community structure in intertidal ecosystems. Understanding this interplay between neighboring communities of sedentary species is therefore essential for effective conservation and restoration of soft-bottom intertidal communities.
\end{abstract}

Key words: Cerastoderma edule; community structure; competition; facilitation; intertidal ecosystem; Mytilus edulis: scale-dependent effect: Schiermonnikoog, The Netherlands; stress alleviation; Wadden Sea.

\section{INTRODUCTION}

In the last two decades, studies from a wide range of terrestrial and marine ecosystems have demonstrated that interactions between sedentary organisms can generate spatial patterns at a landscape level (e.g., Connell 1961, Paine 1974, Dayton 1975, Maron and Harrison 1997, Klausmeier 1999, Guichard et al. 2003). The interplay between small-scale facilitation and longrange inhibition of organisms generates regularly patterned ecosystems, a form of spatial self-organization

Manuscript received 11 January 2012; revised 19 September 2012; accepted 2 October 2012. Corresponding Editor: P. T. Raimondi.

${ }^{8}$ E-mail: s.donadi@rug.n1
(Rietkerk and van de Koppel 2008). An opposite interplay between local competition and large-scale facilitation has been observed on cobble beaches, where various forb species were facilitated behind stands of the cordgrass Spartina alterniflora Loisel. (Bruno 2000), but were outcompeted within the dense Spartina beds (van de Koppel et al. 2006). These studies have in common that intra- and interspecific interactions between sedentary species are scale dependent, as they change in intensity, and even sign, with distance among the organisms under consideration.

The concept of scale-dependent interactions has mainly been used to explain spatial patterns of vegetation. Little is known about the importance of scale-dependent interactions between sedentary animals (van de Koppel et al. 2005). Moreover, to what extent 
such interactions determine the structure of neighboring communities has rarely been investigated. Nevertheless, understanding such spatial interactions may be necessary for the ecological conservation of ecosystems in which the structure of the community living in one habitat depends on interspecific interactions with species in neighboring habitats (Gaines and Roughgarden 1987, Rilov and Schiel 2011).

In this study, we investigated whether negative effects on food availability and sediment properties, combined with positive effects on hydrodynamic conditions by reef-forming blue mussels (Mytilus edulis), result in scale-dependent effects of mussel beds on edible cockles (Cerastoderma edule) on intertidal mudflats in the Dutch Wadden Sea. Blue mussels are well-known ecosystem engineers that decrease near-bed hydrodynamic stress (Widdows et al. 1998, Widdows and Brinsley 2002, Widdows et al. 2002, Gutierrez et al. 2003) and increase sediment organic content through production and deposition of feces and pseudofeces, processes that affect both the mussel bed itself and the surrounding tidal flat (Graf and Rosenberg 1997, Bergfeld 1999, van der Zee et al. 2012). While cockle recruitment and persistence may be positively affected by decreased hydrodynamic stress (Bouma et al. 2001), cockle survival may be negatively affected by adverse lowoxygen sediment conditions created by the accumulation of organic material (Wegeberg and Jensen 1999). Furthermore, by their filter feeding, mussels locally reduce algae concentrations in the benthic boundary layer (Frechétte et al. 1989). As cockles are also filter feeders, blue mussels can compete with cockles for food over larger distances due to the directional flow of water in intertidal habitats (Asmus et al. 1992, Kamermans 1993). There is a rich literature on the formation of spatial patterns within mussel beds due to the scaledependent interplay of facilitation and competition between mussels (Gascoigne et al. 2005, van de Koppel et al. 2005, van de Koppel et al. 2008). However, no study has reported on how scale-dependent effects extend beyond the boundaries of a mussel bed to affect neighboring communities at larger distances.

We hypothesized that cockle abundances may be enhanced at a distance from mussel beds because mussel beds (1) inhibit cockle growth locally by competition for food and by creating adverse sediment conditions (anoxia), and (2) promote the settlement of cockle spat at larger distances through reduction of hydrodynamic stress. As the size and protective status of mussel beds precludes manipulative experiments of the effects on their surroundings, we applied a comparative approach in which we confronted our hypotheses with multiple lines of evidence, following Holling's "adaptive inference" methodology (Holling and Allen 2002). To test our hypotheses, we measured cockle abundances and abiotic variables along transects across three intertidal mussel beds and nearby areas without mussels. At one of the sites where these patterns were observed, we carried out field transplantations of cockles where we investigated if cockle settlement, survival, and growth rates within and close to the mussel reef correlated to changes in food availability, sediment chemistry, and hydrodynamic conditions. Our results suggest that an interplay between local inhibition and longer-range facilitation results in maximal cockle abundance at a distance from mussel beds where positive effects on larval settlement outweigh negative effects on cockle growth and survival.

\section{Methods \\ Field surveys}

The first field survey was conducted in April-May 2009 in the intertidal zone of the Dutch Eastern Wadden Sea, just south of the island of Schiermonnikoog, The Netherlands. The intertidal mudflats in the area are mostly dominated by the bioturbating lugworm Arenicola marina but also harbor several large mussel beds, each $>1$ ha. To study the effect of blue mussels on cockles, we first sampled three transects perpendicular to the coast across a $100 \times 150 \mathrm{~m}$ mussel bed $\left(53^{\circ} 28^{\prime} 8^{\prime \prime} \mathrm{N}\right.$, $6^{\circ} 13^{\prime} 27^{\prime \prime}$ E) and three additional transects at the same elevation in a nearby area without mussel beds $\left(53^{\circ} 28^{\prime} 7^{\prime \prime}\right.$ $\left.\mathrm{N}, 6^{\circ} 13^{\prime} 52^{\prime \prime} \mathrm{E}\right)$. Along each transect, we measured cockle (Cerastoderma edule) abundance, sediment characteristics, and sediment pore water every $50 \mathrm{~m}$. Local cockle abundances were determined by counting individuals within a $0.5 \times 0.5 \mathrm{~m}$ frame, and sediment samples were collected for two depth ranges $(0-1 \mathrm{~cm}$ and $0-5 \mathrm{~cm})$ using a polyvinyl chloride (PVC) corer with an internal diameter of $3 \mathrm{~cm}$. Pore water samples were collected in airtight $50-\mathrm{mL}$ syringes using ceramic soil moisture samplers (Eijkelkamp Agrisearch Equipment, Giesbeek, The Netherlands). Within two hours after collection, pore water oxidation-reduction potential (redox) was measured with a Sentix ORP probe connected to a Multi $340 \mathrm{i}$ voltmeter (WTW, Weilheim, Germany). Silt content of the $0-1 \mathrm{~cm}$ sediment samples (fraction $<63$ $\mu \mathrm{m})$ was determined with a particle-size analyzer (Malvern Particle Sizer 2000; Malvern Instruments, Malvern, Worcestershire, UK) following freeze-drying of the sediment samples. Organic matter content was estimated from ovendried $\left(48 \mathrm{~h}\right.$ at $\left.95^{\circ} \mathrm{C}\right) 0-5 \mathrm{~cm}$ samples as loss on ignition $\left(5 \mathrm{~h}\right.$ at $\left.550^{\circ} \mathrm{C}\right)$.

In May 2011, we performed additional surveys at two other mussel beds $\left(53^{\circ} 28^{\prime} 2^{\prime \prime} \mathrm{N}, 6^{\circ} 10^{\prime} 59^{\prime \prime} \mathrm{E} ; 53^{\circ} 29^{\prime} 44^{\prime \prime} \mathrm{N}\right.$. $\left.6^{\circ} 19^{\prime} 20^{\prime \prime} \mathrm{E}\right)$ and at corresponding areas without mussels $\left(53^{\circ} 28^{\prime} 7^{\prime \prime} \mathrm{N}, 6^{\circ} 11^{\prime} 33^{\prime \prime} \mathrm{E} ; 53^{\circ} 29^{\prime} 51^{\prime \prime} \mathrm{N}, 6^{\circ} 19^{\prime} 48^{\prime \prime} \mathrm{E}\right)$ in Schiermonnikoog to test the generality of the observed patterns. In each survey, variation in cockle abundances was determined as described along three transects from each mussel bed toward the coast and three transects at the same elevation in a nearby area without mussel beds.

\section{Field transplantation experiments}

The initial field surveys showed a peak in cockle abundance at about $100 \mathrm{~m}$ coastward from the mussel bed, while cockle abundances within the mussel bed and 
in the area without mussels were extremely low (see Results: Field surveys: spatial pattern of abiotic parameters and cockle abundance). To test if this pattern was caused by scale-dependent effects of mussels on cockles, a field transplantation experiment was carried out following the field surveys. Due to logistical constraints, we had to limit our experiment to a single mussel bed. We chose four experimental locations: (1) "mussel bed" (bare patches between the mussel aggregations inside the mussel bed); (2) "coastward of the mussel bed" at a distance of $\sim 100 \mathrm{~m}$ coastward from the mussel bed, where we determined the peak in cockle abundance; (3) in a sandy area without mussels at the same elevation as the mussel bed ("lower sandy site"); and (4) in a sandy area without mussels at the same elevation relative to mean sea level as the area of the cockle peak ("upper sandy site"). At each location we randomly designated four $1 \times 1 \mathrm{~m}$ experimental plots (Appendix A). Naturally occurring densities of Cerastoderma edule varied greatly among sites. We found an average density of 225 cockles per square meter $(n=20$ ) coastward of the mussel bed, while in all other locations densities were $<1 / \mathrm{m}^{2}$. In order to minimize potential density-dependent effects due to the presence of cockles (e.g., competition for space, settlement facilitation/inhibition), 225 adult cockles were transplanted in May 2009 from the area coastward of the mussel bed to the plots at each of the two sandy sites and inside the mussel bed. Persistence of a high density of cockles in the plots was checked and confirmed at the end of the experiments.

To test whether the vicinity of mussels affected cockle growth and survival, we added 10 tagged cockles to the $0.9 \times 0.9 \mathrm{~m}$ center area of each plot at the end of May 2009. Young cockles (2-3 years old; $12-26 \mathrm{~mm}$ shell length) were collected from a nearby mudflat, transferred to the lab, measured (shell length, using a vernier caliper), tagged with a plastic label glued to the shell with cyanoacrylate and added to the experimental plots. Nearly four months later (September 2009), all cockles were collected by hand-raking. To avoid edge effects, only the $0.9 \times 0.9 \mathrm{~m}$ center area of each plot was sampled. The number of recaptured, tagged cockles was used to compare in situ survival of juveniles, while cockle spat (3-12 $\mathrm{mm}$ long individuals), which settle in the Wadden Sea from the end of May until the end of June (van der Veer et al. 1998; R. Dekker, personal observation), were counted to examine effects on recruitment and settlement success.

\section{Measurements of chlorophyll a content and hydrodynamic conditions}

Since mussel beds may facilitate settlement of cockle spat in the wake of the reef through reduction of water flow velocities, we investigated the effect of the mussel bed on hydrodynamic conditions. For this, we simultaneously measured current velocity at the site coastward of mussels (at $100 \mathrm{~m}$ from the reef) and in its corresponding site without mussels (upper sandy site), at $5 \mathrm{~cm}$ above the sediment bed in $1-\mathrm{Hz}$ intervals during four consecutive tidal cycles in July. For this purpose, we fixed two acoustic Doppler current profilers (Nortek Aquadopp; Nortek, Rud, Norway) in the sediment with a stainless steel frame.

Furthermore, we measured water chlorophyll $a$ content as a proxy for concentrations of suspended algae and suspended sediment at each site. Water samples were taken at $10 \mathrm{~cm}$ above the sediment in the middle of incoming tide, when water speed was highest. In total, we simultaneously sampled both sites three times across a two-week period in August. After collection, each sample was filtered over two precombusted $\left(3 \mathrm{~h}\right.$ at $450^{\circ} \mathrm{C}$ ), preweighed $\mathrm{GF} / \mathrm{F}$ glass fiber filters (Whatman, Maidstone, Kent, UK) in standardized aliquots in a dark room. Suspended sediment concentrations were determined from the first filter as the mass difference between the initial filter and the dried filter sample $\left(24 \mathrm{~h}\right.$ at $\left.70^{\circ} \mathrm{C}\right)$. Chlorophyll $a$ content was determined from the second filter by acetone extraction following Jeffrey and Humphrey (1975).

\section{Measurements of sediment erosion and cockle spat abundance}

Reduction of water flow velocity coastward of mussel reefs in the study area was confirmed in March 2012 by additional measurements of plaster dissolution along four transects perpendicular to the coast across a mussel bed, and four transects at the same elevation in a sandy area without mussels. Dissolution cylinders $(6.3 \mathrm{~cm}$ long, $2.4 \mathrm{~cm}$ diameter) were molded with model plaster (Knauf Modelgips; Knauf B.V., Utrecht, The Netherlands), dried, weighted, and placed in the field for four tidal cycles (about $46 \mathrm{~h}$ ), after which they were retrieved and dried until constant mass. To account for difference in the exposure time between sites, plaster mass loss values were divided by the average tidal submersion time of each site estimated by means of Sensus Ultra pressure loggers (Reefnet, Mississauga, Ontario, Canada). Cockle spat abundances along the transects were measured by counting individuals (3-12 mm long) within a $0.5 \times 0.5$ $\mathrm{m}$ frame.

\section{Statistical analyses}

The effect of site on the number of recaptures and cockle recruits was analyzed by fitting general linear models. Error distributions were selected based on the lowest Akaike's information criterion or on comparison of residual patterns. We assumed Poisson and negative binomial error distributions for the number of recaptures and spat fall densities, respectively, both with loglink functions. When possible, multiple comparisons were performed via contrast coefficients through the "glht" function from the Multcomp package in R, version 1.2-9 (Hothorn et al. 2008).

To compare growth rate of recaptured, tagged cockles, the effect of initial size on growth was removed by fitting an equation to the pooled data set of initial 
and final lengths, and residuals were calculated. We used the von Bertalanffy growth model as modified by Ramón (2003):

$$
L_{2}=L_{1}+\left(L_{\infty}-L_{1}\right)\left(1-e^{-k \Delta t}\right)
$$

where $L_{1}$ and $L_{2}$ are, respectively, the initial and final lengths, and $\Delta t$ is the time elapsed between $L_{1}$ and $L_{2}$. The parameter $\Delta t$ was assigned a value of $0.8 \mathrm{yr}$ because the experiments were carried out during the growth season. The parameters $L_{\infty}$ and $k$ were estimated by a nonlinear least-squares method using the Gauss-Newton algorithm that yielded $L_{\infty}=29.711 \mathrm{~mm}$ and $k=1.423 / \mathrm{yr}$ $(n=28$, residual sum of squares $=8.599, r=0.945)$. Residual averages of each plot were compared by onefactor analysis of variance (ANOVA) to investigate effects of site on cockle growth, and Tukey's HSD test was used for post hoc comparisons. As tagged cockles in the lower control were recaptured in only one plot, this site was excluded from the analysis (see Results: Field transplantation of cockles: effects on cockle growth and survival ).

Effects of site and sampling time on chlorophyll $a$ content, suspended sediment matter, and water current velocity were tested in three separate models. The direction of the water current (incoming vs. outgoing) was also included as an explanatory variable when analyzing water current velocity data. Independence of observations taken at the same site or time interval was tested by comparing generalized least-squares (GLS) models with and without a residual correlation structure (Zuur et al. 2009). For current velocity data, a significant correlation (likelihood ratio test statistic, LRT = 14.06610; $P<0.05$ ) was found between values observed within the same time interval. We calculated an intraclass correlation of 0.96 and used this value to calculate the design effect and the effective sample size (Snijders and Bosker 1999). The likelihood ratio test statistic (LRT) is used to compare two nested models. It is computed as a difference in likelihood: LRT = $-2 \ln$ (likelihood for model $1 /$ likelihood for model 2).

To confirm the effect of mussel reefs on hydrodynamic conditions, a one-way ANOVA was used to compare values of plaster dissolution measured in four locations along transects: at $100 \mathrm{~m}$ seaward of the mussel bed, at $50 \mathrm{~m}$ coastward of the mussel bed (where a peak in cockle abundance was previously observed), and in the sandy site without mussels at the same elevation, respectively. Tukey's HSD test was used for post hoc comparisons. The relationship between plaster mass loss and cockle spat abundance in the absence of mussel beds was investigated for data collected in the site without mussels by means of a quantile regression on the natural log-transformed data.

When needed, normality assumption was checked using both a normal quantile plot and Shapiro-Wilks test $(P=0.05)$, and homoscedasticity was assessed by comparing GLS models with different residual variance structures (Zuur et al. 2009). All statistical calculations were carried out in $\mathrm{R}$ (Comprehensive $\mathrm{R}$ Archive Network 2010).

\section{RESULTS}

\section{Field surveys: spatial pattern of abiotic parameters and cockle abundance}

The combined surveys from 2009 and 2011 strongly suggested that the mussel bed affected the structure of the intertidal community at both the site of the bed and on its surroundings. Most importantly, the presence of the mussel bed was associated with the occurrence of cockle beds at a distance (see Plate 1); the survey of 2009 showed that cockle densities in the mussel bed transects peaked $100 \mathrm{~m}$ coastward from the bed at $225 \pm 62.53$ individuals $/ \mathrm{m}^{2}$ (mean $\pm \mathrm{SE}$ ), sharply declined to zero within the bed, and then slightly increased seaward from the bed (Fig. 1A). In contrast, cockle abundance along the transects in the area without mussels did not change with distance from land. The spatial pattern in cockle distribution relative to the mussel bed was confirmed by the surveys conducted in 2011 at two other mussel beds (Fig. 1B, C). In both mussel areas, cockle abundance peaked at $50 \mathrm{~m}$ coastward from the beds, while little variation was observed in the corresponding areas without mussels. Hence our surveys suggested a spatial covariation of mussels and cockles between neighboring communities of these sedentary species.

A clear difference in abiotic parameters was found between the mussel transects and the area without mussels. We found a strong increase in silt content and organic matter toward the mussel bed with maximum values inside of $46.92 \% \pm 7.74 \%$ and $6.98 \% \pm 0.74 \%$, respectively (Fig. 2A, B; mean $\pm \mathrm{SE}$ ). In contrast, sediment pore water redox decreased sharply toward the mussel bed with a minimum value of $-382 \pm 6.08 \mathrm{mV}$ inside the bed (Fig. 2C). Silt content, organic matter, and redox showed little variability in the area without mussels (Fig. 2A-C).

\section{Field transplantation of cockles: effects on cockle growth and survival}

Our experiments show that survival and recruitment of cockles were higher on the coastward side of the mussel bed, compared to within the bed or in any of the sandy areas without mussels. Over $50 \%$ of the tagged cockles were found back coastward of the mussel bed, while $\leq 8 \%$ were found in the mussel bed or in any of the sandy sites (site effect, likelihood ratio test statistic, $\mathrm{LRT}=26.81, \mathrm{df}=$ $3, P<0.001$; Fig. 3A). Likewise, we found higher densities of recruits (juvenile cockles of 3-12 $\mathrm{mm}$ ) coastward of the mussel bed $\left(\sim 10 / \mathrm{m}^{2}\right)$ compared to the other sites, where hardly any juveniles were collected (site effect, LRT = 64.00, df $=3, P<0.001$; Fig. 3B). In contrast, cockle growth was generally negatively affected by the mussel bed. Analysis of variance of mean growth residuals revealed a significant effect of site $\left(F_{2,7}=8.23, P<\right.$ 0.015 ), such that growth in the upper sandy site was significantly higher compared to coastward of the mussel 

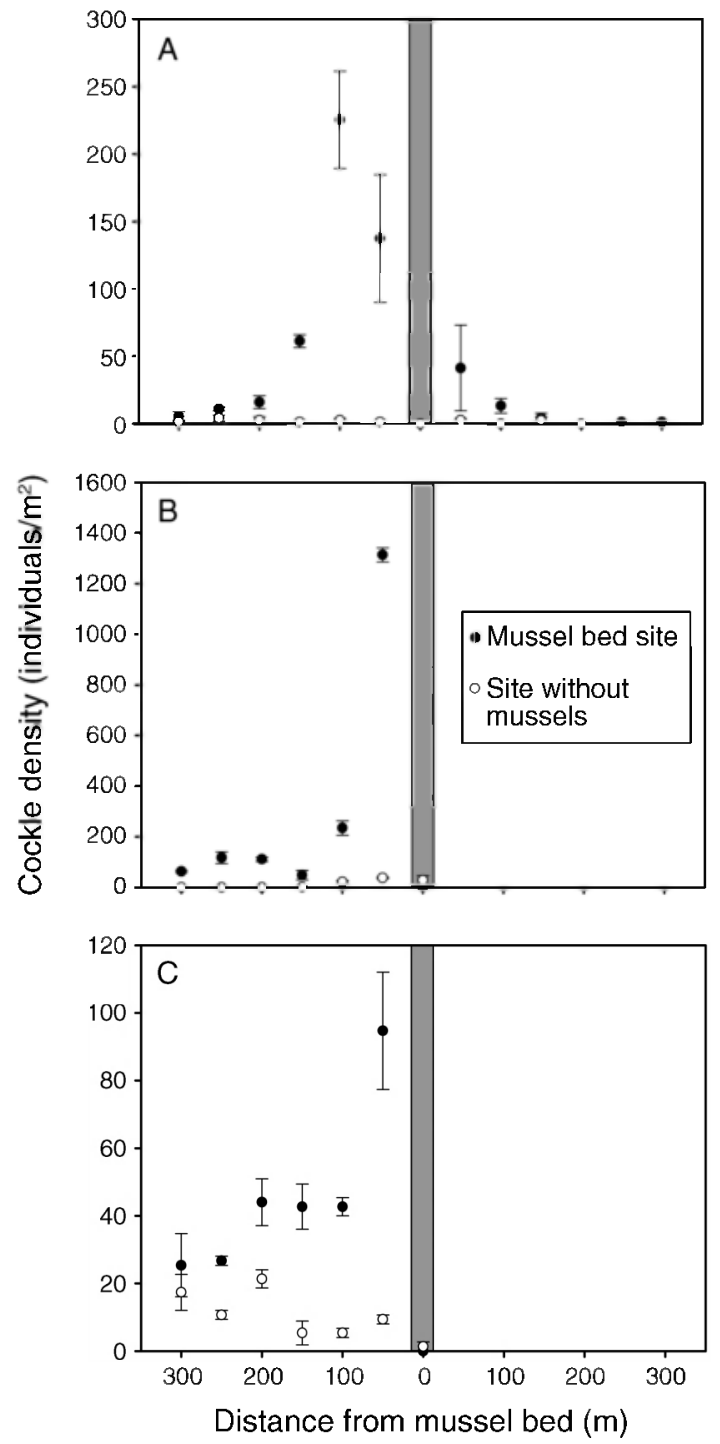

Coastward

Seaward

FIG. 1. Cockle (Cerastoderma edule) density along transects perpendicular to the coast across three intertidal mussel (Mytilus edulis) beds (solid circles) and three corresponding areas without mussels at the same tidal elevation (open circles) in (A) 2009 and (B, C) 2011 in Schiermonnikoog. The Netherlands. The $x$-axis represents the distance from the mussel reef along the mussel bed transects. The gray area indicates the position of the mussel bed. Counts of cockles are within three $0.5 \times 0.5 \mathrm{~m}$ frames. Data are presented as mean $\pm \mathrm{SE}$.

bed (Tukey's HSD post hoc test; $P=0.046$ ) and inside the mussel bed (Tukey's HSD post hoc test; $P=0.014$; Fig. $3 \mathrm{C})$. This suggests that improved survival of cockles at the spat or juvenile stage is the main driver of the high abundance that we observed coastward of the mussel beds.

\section{Variation in chlorophyll a content and hydrodynamic conditions}

We found that the mussel bed likely influenced both food availability for other filter feeders and hydrody- namic conditions. Chlorophyll $a$ content $\left(F_{14}=17.17, P\right.$ $=0.014)$, suspended sediment concentration $\left(F_{1.4}=\right.$ $17.08, P=0.014)$, and water current velocity $\left(F_{1,6}=\right.$ $69.05, P<0.001$ ) were lower coastward of the mussel bed than in the site without mussels (Fig. 4A-C), and no differences were observed between sampling times (main effect and interactions of time were not significant; $P>$ 0.05 ). For current velocity, we found an interaction between site and water current direction $\left(F_{1,6}=167.90\right.$,
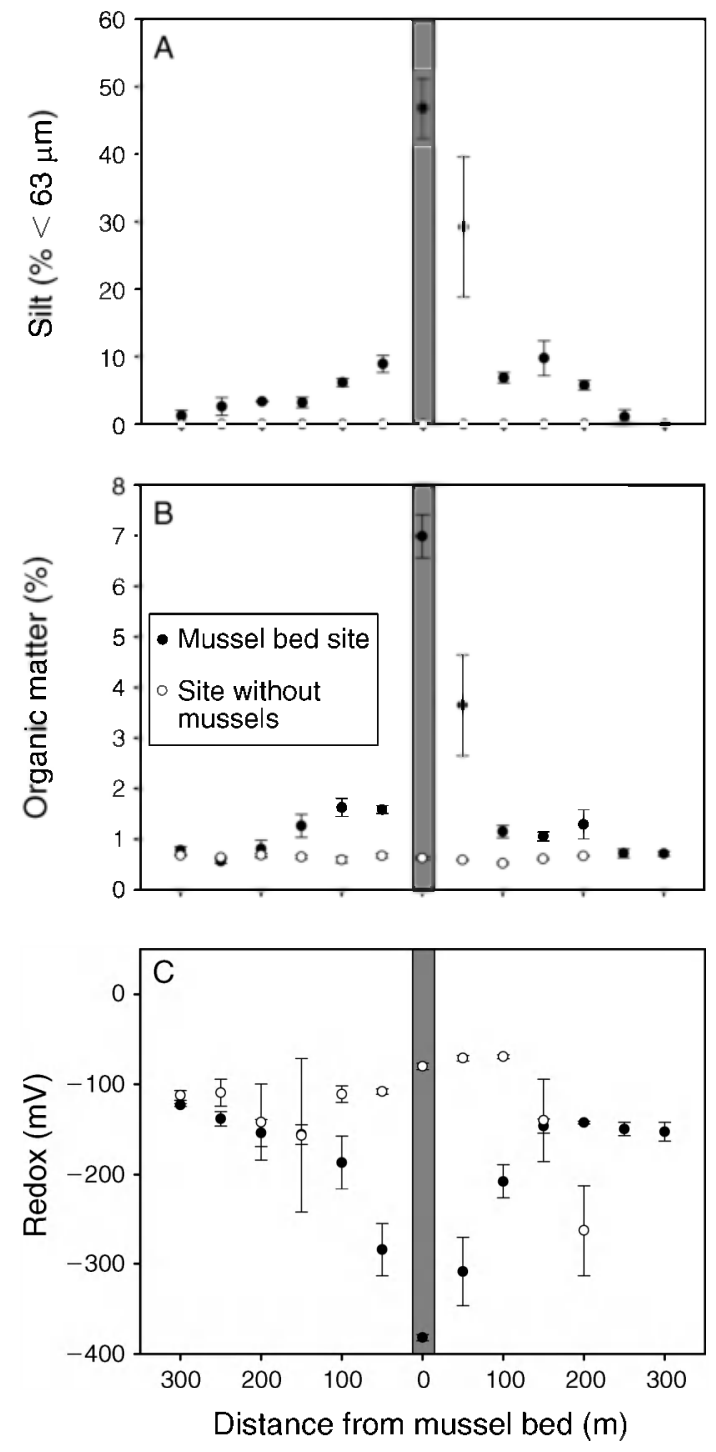

Coastward

Seaward

FIG. 2. (A) Silt content of three PVC corers (internal diameter of $3 \mathrm{~cm}$ ) taken at $0-1 \mathrm{~cm}$ depth. (B) organic matter content of three PVC corers (internal diameter of $3 \mathrm{~cm}$ ) taken at $0-5 \mathrm{~cm}$ depth, and (C) redox potential of three airtight $50-\mathrm{mL}$ syringes, all along transects perpendicular to the coast across an intertidal mussel bed (solid circles) and a corresponding area without mussels at the same tidal elevation (open circles). The $x$-axis represents the distance from the mussel reef along the mussel bed transects. The gray area indicates the position of the mussel bed. Data are presented as mean $\pm \mathrm{SE}$. 

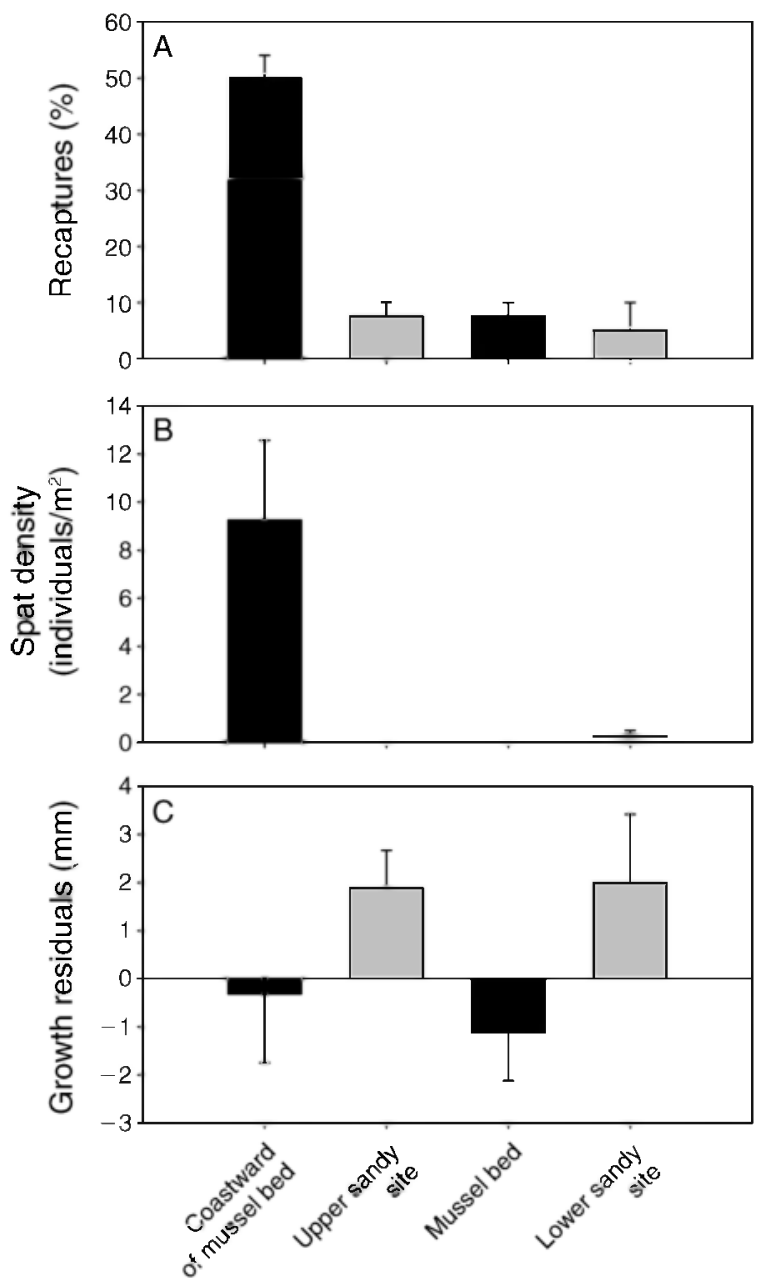

FIG. 3. (A) Percentage of recaptured tagged cockles as an average of four $1-\mathrm{m}^{2}$ plots. (B) cockle spat density as an average of four $1-\mathrm{m}^{2}$ plots, and (C) growth residuals measured coastward of the mussel bed ( $n=20$ recaptured tagged cockles). at a comparable tidal elevation in the area without mussels (upper sandy site, $n=3$ ), within the mussel bed ( $n=3$ ), and at a comparable tidal elevation in the area without mussels (lower sandy site, $n=2$ ). Growth residuals are residuals calculated after fitting an equation (modified from the von Bertalanffy growth model; see Methods: Statistical analyses) to the pooled data set of initial and final lengths of tagged cockles. Data are presented as mean $+\mathrm{SE}$.

$P<0.001$ ), revealing a $21 \%$ lower current velocity coastward of the mussel bed compared to the area without mussels with rising tide, but no significant difference during outgoing water. Our results therefore imply that mussels may affect cockle survival in two opposite directions: by depleting food availability in the water column and by providing shelter to new recruits from waves and water currents.

\section{Sediment erosion and cockle spat abundance}

Reduction of hydrodynamic forces coastward of mussel beds in the study area was confirmed by data collected along transects: plaster mass loss measured at
$50 \mathrm{~m}$ coastward of the reef (where a peak in cockle abundance was previously observed) was decreased by $20 \%$ compared to seaward of the reef (significant oneway ANOVA result, $F_{3,12}=16.18, P<0.001$; Tukey's HSD post hoc test; $P=0.001$ ) and by $21 \%$ compared to
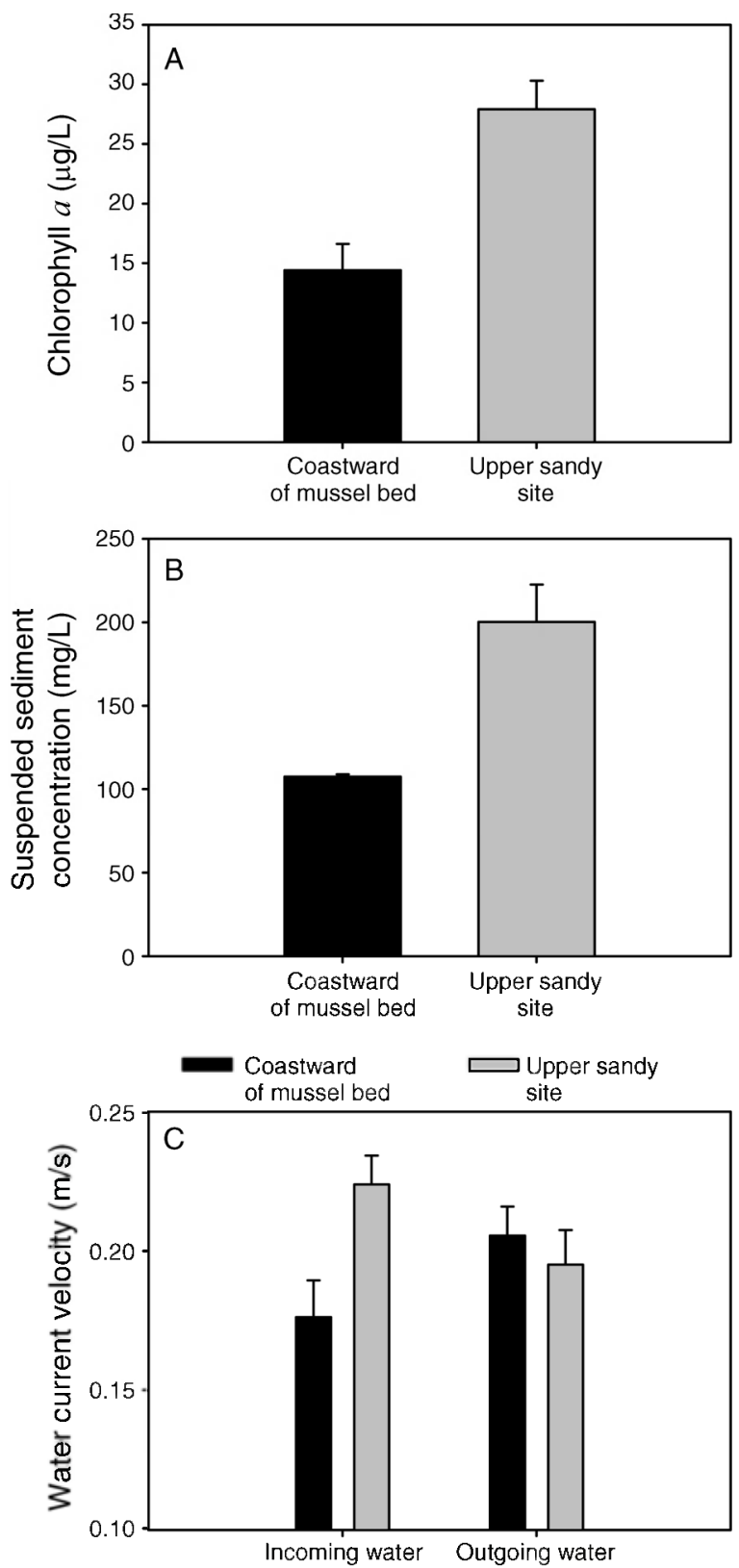

FIG. 4. (A) Chlorophyll a content and (B) suspended sediment concentration in the water column coastward of the mussel bed and at a comparable tidal elevation (upper sandy site). Chlorophyll $a$ and suspended sediment were collected from three filters at three different times. (C) Water current velocity measured during incoming and outgoing water coastward of the mussel bed and at a comparable tidal elevation (upper sandy site). Water current velocity was measured with an acoustic Doppler current profiler in four consecutive tidal cycles. Data are presented as mean $+\mathrm{SE}$. 


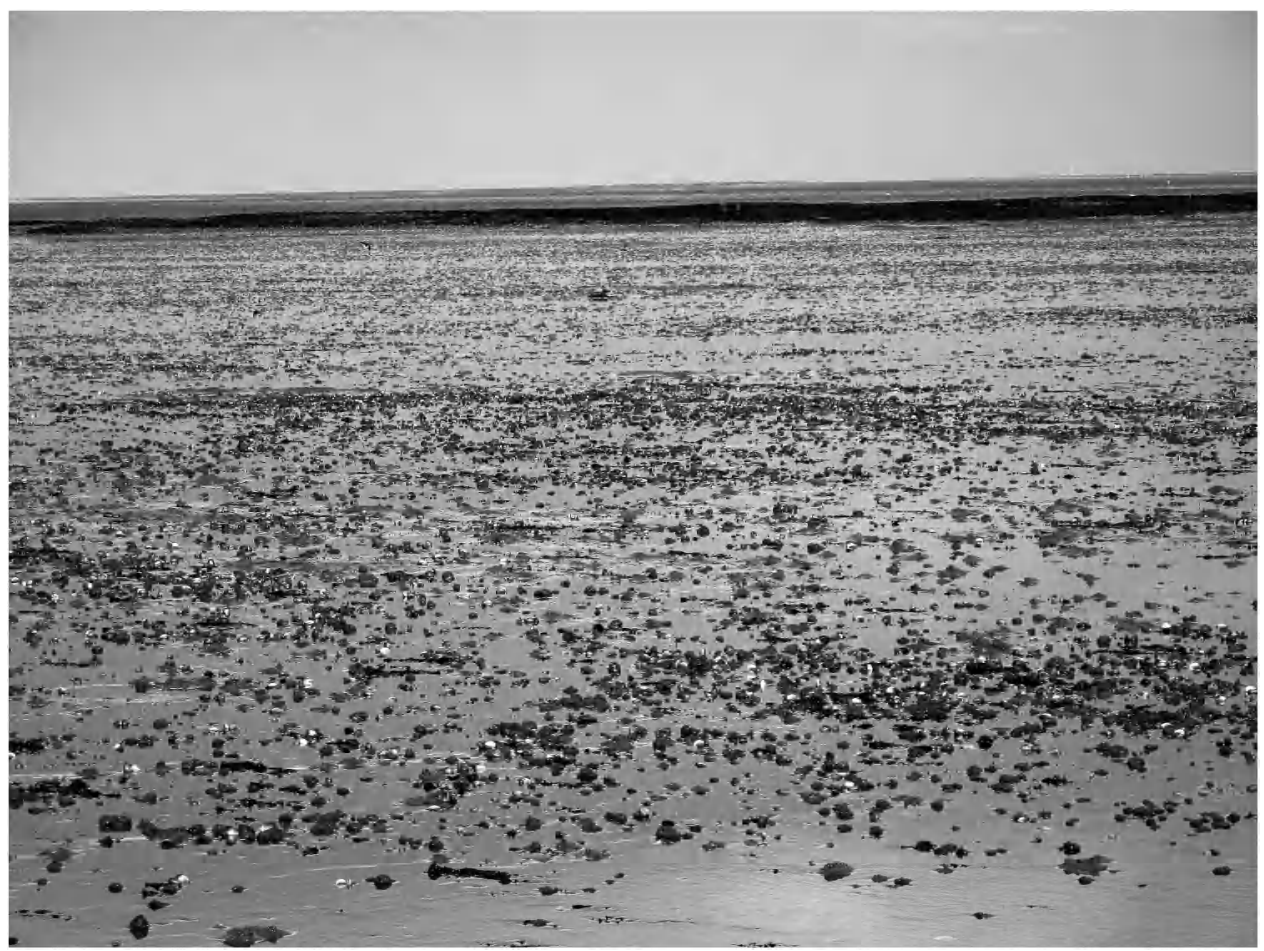

Plate 1. High densities of cockles coastward of a mussel bed in the intertidal flats of Schiermonnikoog. The Netherlands. Photo credit: S. Donadi.

the same tidal elevation in the sandy site (Tukey's HSD post hoc test; $P<0.001$; Appendix B). Our measurements strongly suggest that cockle spat settlement and survival observed in an area without mussels are affected by hydrodynamic stress and sediment erosion; we found a negative relationship between high spat densities (quantile 0.90 ) and plaster mass loss $(n=32, P=$ 0.023 ), with high spat densities never occurring at high values of sediment erosion (Appendix $C$ ). This indicates that cockle bed settlement and survival may be possible only below a certain threshold of hydrodynamic stress, which is lower than the values measured in the area without mussels $(43.91 \% \pm 1.60 \%$ plaster mass loss) and higher than the values observed coastward of the mussel bed $(32.30 \% \pm 1.16 \%$ plaster mass loss; mean $\pm \mathrm{SE})$.

\section{Discussion}

We found that cross-habitat interactions can play an important role in determining the community structure of sedentary species in soft-bottom intertidal systems. Enhanced densities of cockles were observed coastward of reef-forming mussels, but not within the reef itself or in the areas without mussels. Our experiments suggest that this pattern of cockle distribution is caused by a scale-dependent influence of the mussel bed on the survival and growth of cockles. Cockles experienced strong competition for food by mussels within the mussel bed, while spat fall and juvenile survival profited from reduced hydrodynamic stress coastward of the mussel bed. These results emphasize the importance of mussels as ecosystem engineers that shape soft-bottom intertidal communities and reveal that their influence may extend well beyond the boundaries of the actual reefs. Moreover, it emphasizes that intertidal ecosystems can be structured by long-distance interactions, suggesting that protection of specific intertidal habitats requires consideration of its linkages to other habitats in the surroundings.

When studying the effects of mussel reefs on the surroundings, strong inference methods, implying replicated experimental removal of entire beds, are not feasible because of the scale and protective status of mussel reefs. Therefore, we confronted our hypotheses to multiple lines of supportive evidence, following Holling's adaptive inference approach. First, we found a decline in chlorophyll $a$ and low oxygen content in the sediment within and coastward of the mussel bed, relative to the site without mussels at the same tidal elevation. This points to the proposed short-range negative effects of mussels on cockles imposed by the combined effects of intense competition for food and deteriorated sediment conditions. These observations are in close agreement with other studies revealing reduced cockle growth close to mussel beds due to algal depletion (Kamermans 1993, Ramón 1996). Also, deteriorated sediment conditions (e.g., low oxygen content, high organic matter) have been previously reported to hinder survival of many benthic species (Pearson and Rosenberg 1978, Diaz and Rosenberg 
1995, Gray et al. 2002, Hyland et al. 2005, Magni et al. 2008).

A striking opposite effect of mussels on cockles appears to occur at a larger spatial scale. Our results show that cockle densities were greatly enhanced coastward of mussel beds, compared to sites without mussels, and that this may be explained by reduced hydrodynamic stress caused by the mussel bed. Hydrodynamic forces are known to have a strong influence on the settlement and recruitment of larvae, though in contrasting ways. Flow speed can have positive effects on larval settlement (i.e., by increasing larval supply and the contact rate with the substrate) (Judge and Craig 1997, de Montaudouin et al. 2003). However, evidence from the field often showed opposite results (Armonies and Hellwig-Armonies 1992, Bouma et al. 2001, Jonsson et al. 2004). High flow speed decreases the time available for larval adhesion and increases the drag force, detaching the larvae from the substrate (Abelson and Denny 1997). Reef-forming mussel beds can enhance the settlement of larvae and post-larvae by alleviating hydrodynamic stress imposed by waves and water flow (Widdows and Brinsley 2002, Gutierrez et al. 2003, Commito et al. 2005). In agreement with these studies, we measured higher recapture rates of tagged cockles and spat densities at $100 \mathrm{~m}$ coastward of a mussel bed, where field measurements revealed a peak in cockle abundance and reduced water flow, suggesting an increased survival relative to the sites without mussels. Hence at a larger spatial scale, the positive effects of reduced wave action on spat fall seem to outweigh the negative effects of increased competition, explaining the high densities of cockles coastward of the mussel bed.

An alternative explanation for the observed high cockle survival in the wake of the mussel bed is that predation by birds, flatfishes and crustaceans (Sanchezsalazar et al. 1987, Norris and Johnstone 1998, van der Veer et al. 1998) is reduced here for some reason. Yet we documented much higher abundances of cockle predators, such as Eurasian Oystercatchers (Haematopus ostralegus) and crabs (Carcinus maenas), within and coastward of the mussel bed (van der Zee et al. 2012) rather than in the area without mussels, where numbers of cockles recaptured and spat fall were lower. This leaves the alleviation of hydrodynamic stress as the best explanation for enhanced cockle settlement and survival in the larger neighborhood of mussel beds. However, our conclusions remain to be confirmed by further studies providing conclusive experimental evidence of the mechanisms investigated.

When these lines of evidence are put together, our results strongly suggest that the interactions between mussels and cockles are scale dependent; competition dominates at a small scale, while facilitation predominates at larger scales. A similar type of interaction has previously been proposed to explain zonation on cobble beaches (van de Koppel et al. 2006), where forbs were facilitated by dense stands of Spartina alterniflora, but only in their wake, at a distance up to $10 \mathrm{~m}$. Within the dense S. alterniflora stands, competition predominated, and no forbs could persist. Our results now suggest that such scale-dependent interactions can also structure soft-bottom intertidal communities at scales up to 250 $\mathrm{m}$, linking mussel bed habitats to the cockle-dominated tidal flat that lies in their wake. In this way, long-range effects of reef builders may allow the persistence of productive intertidal communities under conditions that would normally not support such a high spatial complexity and associated biodiversity.

Scale dependence has been proposed as the basic mechanism causing self-organized, regular spatial patterns in ecosystems all over the world, ranging from arid bushlands to boreal peat bogs (see review in Rietkerk and van de Koppel 2008). Self-organization is a process whereby spatial patterns at the global level of a system emerge solely from local interactions among the components of a system (Camazine et al. 2001). Even within mussel beds, regular spatial patterns are found, both at sub-meter scale (van de Koppel et al. 2008) and at 10-m scale (van de Koppel et al. 2005), that seem crucial in minimizing competition, promoting mussel biomass, and increasing mussel bed resilience. Other studies have found self-organized spatial patters in other intertidal habitats, such as mudflats (Van der Heide et al. 2010), tidal freshwater wetlands (van de Koppel and Crain 2006), and salt marshes (van Wesenbeeck et al. 2008). The current study shows that effects of spatial self-organization may scale up to much larger spatial scales than previously shown, affecting the presence and distribution of sedentary communities and species across distances up to several hundred meters. Although at this scale regularity is not prevalent, it emphasizes the importance and reach of self-organization processes in intertidal ecosystems, determining distribution patterns of individuals at meter scale (van de Koppel et al. 2008) to habitats (e.g., cockle beds) at sub-kilometer scale.

Our study suggests that reef-forming organisms can change the balance between abiotic and biotic control over species settlement, growth, and survival over different spatial scales. In the sites without mussels, adverse hydrodynamic conditions likely caused low settlement of juvenile cockles, explaining the lack of cockles in these locations. This confirms that reef builders are indeed important ecosystem engineers that alter hydrodynamic energy and sedimentation processes, both locally (within the reef) and at the tidal flat that lies in their wake (Kroncke 1996, Graf and Rosenberg 1997, Gutierrez et al. 2003). Hence while abiotic stress potentially inhibits cockles in the absence of the mussel reef, biological processes, such as competition for food and interactions through ecosystem engineering, may dominate within and coastward of the mussel bed.

Our results point to the importance of spatial interactions among neighboring communities. As a consequence, intertidal ecosystems can be particularly vulnerable to disturbances that destroy such spatial 
interactions and the resulting structures (Weerman et al. 2011). Because intertidal communities seem to rely on a spatial network of facilitative and competitive interactions at different scales, human perturbations (e.g., the overfishing of ecosystem engineers) can cascade through the ecosystem, leading to unexpected and drastic changes on large spatial and temporal scales (Lotze 2005, Eriksson et al. 2010). On the other hand, our results suggest that successful restoration of soft-bottom ecosystem engineers can have beneficial cascading effects on ecosystems over large areas, increasing spatial complexity and associated biodiversity. Therefore, better understanding of cross-scale interactions among neighboring habitats is essential for effective conservation and restoration of intertidal ecosystems, such as the Wadden Sea.

\section{ACKNOWLEDGMENTS}

This study was financed by a grant from the ZKO program of The Netherlands Organization of Scientific Research (NWO) to B. K. Eriksson, T. van der Heide, E. Weerman, S. Donadi, H. Olff, and E. van der Zee (grant no. 839.08.310), and by a postdoctoral grant from FORMAS to J. S. Eklöf (grant no. 2008-839). We thank two anonymous reviewers for helpful comments on the text

\section{Literature Cited}

Abelson, A., and M. Denny. 1997. Settlement of marine organisms in flow. Annual Review of Ecology and Systematics 28:317-339.

Armonies, W., and M. Hellwig-Armonies. 1992. Passive settlement of Macoma balthica spat on tidal flats of the Wadden Sea and subsequent migration of juveniles. Netherlands Journal of Sea Research 29:371-378.

Asmus. H.. R. M. Asmus, T. C. Prins, N. Dankers, G. Frances, B. Maass, and K. Reise. 1992. Benthic-pelagic flux rates on mussel beds: tunnel and tidal flume methodology compared. Helgolander Meeresuntersuchungen 46:341-361.

Bergfeld. C. 1999. Macrofaunal community pattern in an intertidal sandflat: effects of organic enrichment via biodeposition by mussel beds. First results. Senckenbergiana Maritima 29:23-27.

Bouma, H., P. P. de Vries, J. M. C. Duiker, P. M. J. Herman, and W. J. Wolff. 2001. Spatial pattern of early recruitment of Macoma balthica (L.) and Cerastoderma edule (L.) in relation to sediment dynamics on a highly dynamic intertidal sandflat. Journal of Sea Research 45:79-93.

Bruno, J. F. 2000. Facilitation of cobble beach plant communities through habitat modification by Spartina alterniflora. Ecology 81:1179-1192.

Camazine, S., J. L. Deneubourg, N. Franks, J. Sneyd, G. Theraulaz, and E. Bonabeau. 2001. Self-organization in biological systems. Princeton University Press. Princeton, New Jersey, USA.

Commito, J. A., E. A. Celano, H. J. Celico, S. Como, and C. P. Johnson. 2005. Mussels matter: postlarval dispersal dynamics altered by a spatially complex ecosystem engineer. Journal of Experimental Marine Biology and Ecology 316:133-147.

Comprehensive R Archive Network. 2010. R: a language and environment for statistical computing. $\mathbf{R}$ Foundation for Statistical Computing. Vienna, Austria.

Connell. J. H. 1961. Influence of interspecific competition and other factors on distribution of barnacle Chthamalus stellatus. Ecology 42:710-723.

Dayton, P. K. 1975. Experimental evaluation of ecological dominance in a rocky intertidal algal community. Ecological Monographs 45:137-159. de Montaudouin, X., G. Bachelet, and P. G. Sauriau. 2003. Secondary settlement of cockles Cerastoderma edule as a function of current velocity and substratum: a flume study with benthic juveniles. Hydrobiologia 503:103-116.

Diaz, R. J., and R. Rosenberg. 1995. Marine benthic hypoxia: a review of its ecological effects and the behavioural responses of benthic macrofauna. Oceanography and Marine Biology: an Annual Review 33:245-303.

Eriksson, B. K., T. van der Heide, J. van de Koppel, T. Piersma, H. W. van der Veer, and H. Olff. 2010. Major changes in the ecology of the Wadden Sea: human impacts. ecosystem engineering and sediment dynamics. Ecosystems 13:752-764.

Frechétte, M., C. A. Butman. and W. R. Geyer. 1989. The importance of boundary-layer flows in supplying phytoplankton to the benthic suspension feeder, Mytilus edulis L. Limnology and Oceanography 34:19-36.

Gaines, S. D., and J. Roughgarden. 1987. Fish in offshore kelp forests affect recruitment to intertidal barnacle populations. Science 235:479-481

Gascoigne, J. C., H. A. Beadman, C. Saurel, and M. J. Kaiser. 2005. Density dependence, spatial scale and patterning in sessile biota. Oecologia 145:371-381.

Graf, G., and R. Rosenberg. 1997. Bioresuspension and biodeposition: a review. Journal of Marine Systems 11:269278.

Gray, J. S., R. S. S. Wu, and Y. Y. Or. 2002. Effects of hypoxia and organic enrichment on the coastal marine environment. Marine Ecology Progress Series 238:249-279

Guichard, F.. P. M. Halpin, G. W. Allison, J. Lubchenco, and B. A. Menge. 2003. Mussel disturbance dynamics: signatures of oceanographic forcing from local interactions. American Naturalist 161:889-904.

Gutierrez, J. L., C. G. Jones, D. L. Strayer, and O. O. Iribarne. 2003. Mollusks as ecosystem engineers: the role of shell production in aquatic habitats. Oikos 101:79-90.

Holling. C. S., and C. R. Allen. 2002. Adaptive inference for distinguishing credible from incredible patterns in nature. Ecosystems 5:319-328.

Hothorn. T.. F. Bretz. and P. Westfall. 2008. Simultaneous inference in general parametric models. Biometrical Journal $50: 346-363$

Hyland, J., L. Balthis, I. Karakassis, P. Magni, A. Petrov, J. Shine. O. Vestergaard, and R. Warwick. 2005. Organic carbon content of sediments as an indicator of stress in the marine benthos. Marine Ecology Progress Series 295:91-103.

Jeffrey, S. W., and G. F. Humphrey. 1975. New spectrophotometric equation for determining chlorophyll $a, b, c_{1}$ and $c_{2}$. Biochemie und Physiologie der Pflanzen 167:194-204.

Jonsson. P. R., K. M. Berntsson, and A. I. Larsson. 2004. Linking larval supply to recruitment: flow-mediated control of initial adhesion of barnacle larvae. Ecology 85:2850-2859.

Judge. M. L.. and S. F. Craig. 1997. Positive flow dependence in the initial colonization of a fouling community: results from in situ water current manipulations. Journal of Experimental Marine Biology and Ecology 210:209-222.

Kamermans. P. 1993. Food limitation in cockles (Cerastoderma edule (L.)): influences of location on tidal flat and of nearby presence of mussel beds. Netherlands Journal of Sea Research 31:71-81.

Klausmeier. C. A. 1999. Regular and irregular patterns in semiarid vegetation. Science 284:1826-1828.

Kroncke, I. 1996. Impact of biodeposition on macrofaunal communities in intertidal sandflats. Marine Ecology-Pubblicazioni Della Stazione Zoologica Di Napoli I 17:159-174.

Lotze. H. K. 2005. Radical changes in the Wadden Sea fauna and flora over the last 2,000 years. Helgoland Marine Research 59:71-83.

Magni, P., G. De Falco, S. Como, D. Casu, A. Floris, A. N. Petrov. A. Castelli. and A. Perilli. 2008. Distribution and ecological relevance of fine sediments in organic-enriched 
lagoons: the case study of the Cabras lagoon (Sardinia, Italy). Marine Pollution Bulletin 56:549-564.

Maron. J. L.. and S. Harrison. 1997. Spatial pattern formation in an insect host-parasitoid system. Science 278:1619-1621.

Norris, K., and I. Johnstone. 1998. The functional response of oystercatchers (Haematopus ostralegus) searching for cockles (Cerastoderma edule) by touch. Journal of Animal Ecology 67:329-346.

Paine, R. T. 1974. Intertidal community structure: experimental studies on relationship between a dominant competitor and its principal predator. Oecologia 15:93-120.

Pearson. T. H.. and R. Rosenberg. 1978. Macrobenthic succession in relation to organic enrichment and pollution of the marine environment. Oceanography and Marine Biology: an Annual Review 16:229-311.

Ramón. M. 1996. Relationships between the bivalves Mytilus edulis (L.) and Cerastoderma edule (L.) in a soft bottom environment: an example of interaction at small spatial scale. Journal of Experimental Marine Biology and Ecology 204:179-194.

Ramón. M. 2003. Population dynamics and secondary production of the cockle Cerastoderma edule (L.) in a backbarrier tidal flat of the Wadden Sea. Scientia Marina 67:429-443.

Rietkerk, M., and J. van de Koppel. 2008. Regular pattern formation in real ecosystems. Trends in Ecology and Evolution 23:169-175.

Rilov, G.. and D. R. Schiel. 2011. Community regulation: the relative importance of recruitment and predation intensity of an intertidal community dominant in a seascape context. PLOS ONE 6.

Sanchezsalazar. M. E.. C. L. Griffiths, and R. Seed. 1987. The interactive roles of predation and tidal elevation in structuring populations of the edible cockle, Cerastoderma edule. Estuarine Coastal and Shelf Science 25:245-260.

Snijders. T., and R. Bosker. 1999. Multilevel analysis. Sage Publications, London. UK

van de Koppel, J., A. H. Altieri, B. S. Silliman, J. F. Bruno, and M. D. Bertness. 2006. Scale-dependent interactions and community structure on cobble beaches. Ecology Letters 9:45-50.

van de Koppel, J., and C. M. Crain. 2006. Scale-dependent inhibition drives regular tussock spacing in a freshwater marsh. American Naturalist 168:E136-E147.

van de Koppel. J.. J. C. Gascoigne. G. Theraulaz. M. Rietkerk. W. M. Mooij, and P. M. J. Herman. 2008. Experimental evidence for spatial self-organization and its emergent effects in mussel bed ecosystems. Science 322:739-742. van de Koppel, J., M. Rietkerk, N. Dankers, and P. M. J. Herman. 2005. Scale-dependent feedback and regular spatial patterns in young mussel beds. American Naturalist 165:E66-E77.

van der Heide. T., T. J. Bouma. E. H. van Nes, J. van de Koppel, M. Scheffer, J. G. M. Roelofs, M. M. van Katwijk, and A. J. P. Smolders. 2010. Spatial self-organized patterning in seagrasses along a depth gradient of an intertidal ecosystem. Ecology 91:362-369.

van der Veer. H. W.. R. J. Feller, A. Weber, and J. I. J. Witte. 1998. Importance of predation by crustaceans upon bivalve spat in the intertidal zone of the Dutch Wadden Sea as revealed by immunological assays of gut contents. Journal of Experimental Marine Biology and Ecology 231:139-157.

van der Zee, E. M., T. van der Heide, S. Donadi, J. S. Eklöf, B. K. Eriksson. H. Olff. H. W. van der Veer, and T. Piersma. 2012. Spatially extended habitat modification by intertidal reef-building bivalves alters consumer-resource interactions. Ecosystems 15:664-673.

van Wesenbeeck. B. K.. J. van de Koppel. P. M. J. Herman. and T. J. Bouma. 2008. Does scale-dependent feedback explain spatial complexity in salt-marsh ecosystems? Oikos $117: 152-159$.

Weerman. E. J., P. M. J. Herman, and J. Van de Koppel. 2011. Top-down control inhibits spatial self-organization of a patterned landscape. Ecology 92:487-495.

Wegeberg, A. M., and K. T. Jensen. 1999. Reduced survivorship of Himasthla (Trematoda. Digenea)-infected cockles (Cerastoderma edule) exposed to oxygen depletion. Journal of Sea Research 42:325-331.

Widdows, J., and M. Brinsley. 2002. Impact of biotic and abiotic processes on sediment dynamics and the consequences to the structure and functioning of the intertidal zone. Journal of Sea Research 48:143-156.

Widdows, J., M. D. Brinsley, P. N. Salkeld, and M. Elliott. 1998. Use of annular flumes to determine the influence of current velocity and bivalves on material flux at the sediment-water interface. Estuaries 21:552-559.

Widdows, J., J. S. Lucas, M. D. Brinsley, P. N. Salkeld, and F. J. Staff. 2002. Investigation of the effects of current velocity on mussel feeding and mussel bed stability using an annular flume. Helgoland Marine Research 56:3-12.

Zuur, A. F., E. N. Ieno, N. Walker, A. A. Saveliev, and G. M. Smith. 2009. Mixed effects models and extensions in ecology with R. Springer, New York, New York, USA.

\section{Supplemental Material}

Appendix A

Schematic of the field transplantation design (Ecological Archives E094-040-A1).

\section{Appendix B}

Plaster mass loss along transects across a mussel bed and in an area with no mussel beds (Ecological Archives E094-040-A2).

\section{Appendix C}

Relationship between cockle spat densities and plaster mass loss (Ecological Archives E094-040-A3). 